\title{
Einleitung: Die Lehrtätigkeit des Georg Sabinus an der Universität Königsberg
}

\section{Zur Quellenlage}

Georg Sabinus, eigentlich Georg Schuler (1508-1560), ${ }^{1}$ einer der berühmtesten neulateinischen deutschen Dichter des 16. Jahrhunderts und dank der nachdrücklichen Empfehlungen von Seiten seines Förderers Joachim Camerarius und seines Wittenberger Lehrers und Schwiegervaters Philipp Melanchthon seit 1544 erster Rektor der neugegründeten Universität Königsberg, daneben Inhaber der Professur für Poesie und Redekunst, hat neben seinem poetischen Werk auch eine Reihe von Prosatexten veröffentlicht: historische Abhandlungen, Reden und zwei Lehrschriften, die, ebenso wie eine Edition von Ciceros ,Orator‘, unmit-

\begin{abstract}
Anmerkung: Dies ist eine überarbeitete und bibliographisch aktualisierte Fassung meines ebenso betitelten Beitrags in: Die Universität Königsberg in der Frühen Neuzeit. Hg. von Hanspeter Marti u. Manfred Komorowski unter Mitarbeit von Karin Marti-Weissenbach. Köln, Weimar, Wien: Böhlau Verlag 2008 (Publikation der Arbeitsstelle für kulturwissenschaftliche Forschungen, Engi), S. 77-115.
\end{abstract}

1 Immer noch grundlegend für seine Biographie: Max Töppen: Die Gründung der Universität zu Königsberg und das Leben ihres ersten Rectors Georg Sabinus. Nach gedruckten und ungedruckten Quellen dargestellt. Königsberg 1844 (mit Abdruck von Quellentexten). - Unter den neueren biographischen Darstellungen für unseren Zusammenhang von zentraler Bedeutung: Heinz Scheible: Georg Sabinus (1508-1560). Ein Poet als Gründungsrektor. In: Die Albertus-Universität zu Königsberg und ihre Professoren. Aus Anlaß der Gründung der Albertus-Universität vor 450 Jahren hg. von Dietrich Rauschning und Donata von Nerée. Berlin 1995 (Jahrbuch der Albertus-Universität zu Königsberg/Pr. 29 [1994]), S. 17-31; Wilhelm Kühlmann u. Hermann Wiegand: Georg Sabinus. In: VL 1520-1620, Bd. 5 (2016), Sp. 397-407. - Übersicht über sein dichterisches Gesamtwerk bei Georg Ellinger: Geschichte der neulateinischen Literatur Deutschlands im 16. Jahrhundert. Bd. 2. Berlin, Leipzig 1929, Reprint Berlin 1969, S. 67-75. - Ergänzend hierzu noch zu erwähnen: John L. Flood: Poets laureate in the Holy Roman Empire. A bio-bibliographical handbook. Vol. 4. Berlin, New York 2006, S. 1778-1787; Humanistische Lyrik des 16. Jahrhunderts. Lateinisch und deutsch. Ausgew., übers., erläut. u. hg. von Wilhelm Kühlmann u.a. Frankfurt a.M. 1997 (Bibliothek deutscher Klassiker 146 = Bibliothek der Frühen Neuzeit 5), S. 1240-1243; Wilhelm Kühlmann u. Werner Straube: Zur Historie und Pragmatik humanistischer Lyrik im alten Preußen. Von Konrad Celtis über Eobanus Hessus zu Georg Sabinus. In: Kulturgeschichte Ostpreußens in der Frühen Neuzeit. Akten des interdisziplinären Kolloquiums in Rauschen/Swetlogorsk vom 18.-25. September 1994. Hg. von Klaus Garber, Manfred Komorowski u. Axel E. Walter. Tübingen 2000, S. 657-736; Jerzy Starnawski: Die Beziehungen des Humanisten Georg Sabinus (1508-1560) zu Polen. In: Germania latina. Latinitas teutonica. Politik, Wissenschaft, humanistische Kultur vom späten Mittelalter bis in unsere Zeit. Hg. von Eckhard Keßler u. Heinrich C. Kuhn. Bd. 1. München 2003, S. 469-481. 
telbar mit seiner elfjährigen Königsberger Professur bis zu seinem Weggang im Jahre 1555 in Zusammenhang stehen. Die Authentizität nahezu aller dieser Prosaschriften wurde von den beiden Herausgebern der Opera omnia Melanchthons innerhalb des Corpus Reformatorum ${ }^{2}$ in Zweifel gezogen; nach ihrer Auffassung war vielfach nicht Sabinus, unter dessen Namen sie im Druck erschienen sind, sondern Melanchthon der eigentliche Verfasser - weshalb sie auch in dessen Opera omnia aufgenommen wurden. ${ }^{3}$ Ausgenommen von solchen Vorbehalten blieb, soweit ich sehe, nur eine der beiden Königsberger Lehrschriften, die 1551 zuerst erschienenen und später innerhalb der erweiterten Ausgabe der ,Poemata (zuerst 1563) und auch sonst häufig nachgedruckten ,De carminibus ad veterum imitationem artificiose componendis praecepta'. Für die zweite, wesentlich gewichtigere Königsberger Lehrschrift, die 1555 in Wittenberg erschienene ,Fabularum Ovidii interpretatio tradita in Academia Regiomontana', die im Zentrum dieser Darstellung stehen soll, hatte schon Georg Theodor Strobel in der 1781 erschienenen 5. Sammlung seiner ,Miscellaneen literarischen Inhalts“ die Verfasserschaft Melanchthons postuliert, unter Berufung auf eine Rede des Laurentius Ludovicus über Melanchthon. ${ }^{4}$ Heinrich Ernst Bindseil ist Strobel darin gefolgt und hat das Werk unter der Überschrift ,Phil. Mel. Enarratio Metamorphoseon Ovidii' in Band 19 des Corpus Reformatorum abgedruckt. ${ }^{5}$ An der Stelle der Rede des Laurentius Ludovicus, auf die sich Strobel und Bindseil stützen, ist davon die Rede, daß Melanchthon vielen Männern aus seinem Bekanntenkreis, dar-

2 Philipp Melanchthon: Opera quae supersunt omnia. Ed. Carolus Gottlieb Bretschneider (vol. 16 sqq.: ed. Henricus Ernestus Bindseil). 28 vol. Halle a. d. S. (vol. 19 sqq.: Braunschweig) 1834-1860 (Corpus Reformatorum 1-28), Reprint New York, Frankfurt a.M. 1963. Im folgenden wie üblich zitiert mit dem Sigel CR.

3 Dies gilt für die folgenden, hier nach der Chronologie der Erstdrucke aufgeführten Schriften des Sabinus: De utilitate studiorum eloquentiae (1538). In: CR 11 (1843), Sp. 364-373; De electione et coronatione Caroli V. Caesaris historia (1544). In: CR 20 (1854), Sp. 473-514; Oratio habita [...] in funere nobilissimae Dominae Dorotheae, coniugis illustrissimi Principis Alberti (1547). In: CR 11 (1843), Sp. 763-775; Narratio deliberationis Maximiliani Imperatoris Romanorum de bello Turcico (1551). In: CR 20 (1854), Sp. 453-472 (unter dem Titel ,Exhortatio Maximiliani Caesaris ad bellum Turcis inferendum'); Fabularum Ovidii interpretatio (1555). In: CR 19 (1853), Sp. 497-654 (unter dem Titel ,Enarratio Metamorphoseon Ovidii`).

4 Georg Theodor Strobel: Litterarische Nachricht von Melanchthons Declamationen. In: ders.: Miscellaneen literarischen Inhalts gröstentheils aus ungedruckten Quellen herausgegeben. 5. Sammlung. Nürnberg 1781, S. 131-180, hier S. $143 \mathrm{f}$.

5 CR 19 (1853), Sp. 497-654. Der Widmungsbrief an Herzog Albrecht wurde weggelassen. Die Abwandlung der Überschrift erfolgte im Sinne der im Corpus Reformatorum für Melanchthons Scripta philologica getroffenen Sprachregelung, nach der der Begriff interpretatio Übersetzungen vorbehalten bleibt, Scholien bzw. Kommentare hingegen durchweg unter dem Begriff enarratio erfaßt werden. 
unter auch schätzbaren Gelehrten, mit der Abfassung von akademischen Reden und diversen anderen Schriften, die dann unter deren Namen im Druck erschienen, behilflich gewesen sei. Zu der Zahl derer, die sich solcher Dienste erfreuen konnten, habe auch Sabinus gehört, der seinem alten Lehrer die „mythologias in metamorphosin Ovidii“ zu verdanken habe. Die Stelle bei Ludovicus lautet im Zusammenhang:

\begin{abstract}
Publice recitanda, proponenda, disputanda solus ille [Melanchthon] scripsit. Collegis multa praescripsit, neque id docti et ipsi viri turpe sibi putarunt. Vir nobilissimus D. Zieglerus, nobilis linguae hebr. Professor, Lipsia saepe veniens Witebergam petivit sibi lectiones et orationes praescribi, et musei foribus assedit, ne quis scribentem interpellaret. D. Crucigero praescripsit commentarium in Iohannem in lectione ipsius Lutheri, Froschelio, Diacono in Matthaeum; D. Milichio, viro praestantissimo, in secundum Plinii; Chytraeo regulas vitae; Sabino mythologias in metamorphosin Ovidii; D. Klingio ICto iuris methodum; Confessionem Augustanam graecam Dolscio; Orationes multis in Academia Lipsica, Francofurtana, Rostochiana, Gryphiswaldiana; aliis alia innumerabilia. ${ }^{6}$
\end{abstract}

[Öffentliche Vorträge, Bekanntmachungen und Disputationsthesen schrieb jener Mann (Melanchthon) allein. Für seine Kollegen hat er viele schriftliche Ausarbeitungen gemacht, und die Gelehrten, selbst (ausgewachsene) Männer, haben dies für keine Schande gehalten. Der hochberühmte Dr. Ziegler, berühmter Professor der hebräischen Sprache, kam oft von Leipzig nach Wittenberg, erbat sich schriftliche Ausarbeitungen für Vorlesungen und Reden und ließ sich vor der Tür der Studierstube nieder, damit niemand den Schreibenden unterbräche. Für Dr. Cruciger entwarf er, innerhalb einer Vorlesung von Luther selbst, einen Johannes-Kommentar, für den Diakon Fröschel einen Matthäus-Kommentar, für den herausragenden Dr. Milichius einen Kommentar zum zweiten Buch des Plinius; für Chytraeus verfaßte er die ,Regulae vitae', für Sabinus mythologische Erläuterungen zu den Metamorphosen Ovids, für den Rechtsgelehrten Dr. Kling eine Methodik des Rechts, für Dolscius fertigte er eine griechische Übersetzung des Augsburgischen Bekenntnisses, für viele Dozenten an den Universitäten Leipzig, Frankfurt, Rostock und Greifswald schrieb er Reden, und Sonstiges ohne Zahl schrieb er für andere Personen.]

Mir scheint dieser Passus wenigstens im Falle des Sabinus (die anderen entziehen sich meiner Beurteilung) eine so weitgehende Auslegung nicht zu erlauben. Das Verb ,praescribere‘, das Ludovicus hier benutzt, erlaubt auch eine eingeschränktere Deutung, etwa in dem Sinne, daß Melanchthon Sabinus Hinweise oder Materialien zum Verständnis einzelner Partien von Ovids Metamorphosen geliefert hat. Zudem sprechen auch die Angaben über die Drucklegung der ,Fabularum Ovidii interpretatio', die Sabinus in dem von Bindseil weggelassenen Widmungsbrief an Herzog Albrecht von Preußen macht, gegen eine Verfasserschaft Melanchthons im strikteren Sinne. Ein nicht unwichtiges Zeugnis für die Verfas-

6 Zitiert nach ebd., Sp. $497 \mathrm{f}$. 
serschaft des Sabinus liefert sein Schüler Johannes Schosser (1530-1585) ${ }^{7}$ mit seinem drei Jahre nach der ,Fabularum Ovidii interpretatio‘ erschienenen Gedicht ,In mythologica Georgii Sabini' ${ }^{6}{ }^{8}$ in dem er Sabinus rühmt, der erste zu sein, der in der Lage gewesen sei, Licht in die Dunkelheit der Sagenwelt der alten Dichter zu bringen. Ebenso wie Ann Moss, der wir zwei sehr sachkundige Analysen des Werkes im Rahmen der Geschichte der Ovid-Kommentierung seit dem späten Mittelalter zu verdanken haben, ${ }^{9}$ sehe also auch ich keine reale Grundlage für eine Zuschreibung an Melanchthon ${ }^{10}$ und gehe (wie übrigens auch schon der immer noch maßgebliche Sabinus-Biograph Max Töppen ${ }^{11}$ ) davon aus, daß wir es hier in der Tat mit einer Schrift des Sabinus selbst zu tun haben, mag auch das eine oder andere Element darin von Melanchthon beigesteuert worden sein. Nur nebenher sei bemerkt, daß die Argumente der Herausgeber des Corpus Reformatorum für die Zuschreibung anderer Schriften von Sabinus an Melanchthon nicht von besserer Überzeugungskraft sind; sie sind noch oberflächlicher und vermutlich nicht unbeeinflußt von gewissen Vorurteilen gegenüber der Persönlichkeitsstruktur des Sabinus, die als fest verankerte Gemeinplätze die Sabinus-Forschung von altersher geprägt haben. ${ }^{12}$

7 Über ihn siehe meinen Artikel in: VL 1520-1620, Bd. 5. (2016), Sp. 552-564.

8 Ioannes Schosserus: Carminum libellus. Wittenberg: Haeredes Georgii Rhaw 1558, Bl. B5 ${ }^{\mathrm{r}}-$ B5"; Nachdruck in: ders.: Poëmatum libri XI. Frankfurt a.O.: Andreas Eichorn 1585, Bl. Q3 (mit leicht veränderter Überschrift; „In mythologiam Georgii Sabini“). - Text s. o., Vorwort, S. VII.

9 Ann Moss: Ovid in Renaissance France. A survey of the Latin editions of Ovid and commentaries printed in France before 1600. London 1982 (Warburg Institute Surveys 8), S. 48-53; Latin commentaries on Ovid from the Renaissance. Selected, introduced and translated by Ann Moss. Signal Mountain, Tenn. 1998 (Library of Renaissance humanism), S. 143-158.

10 Der auf die Herausgeber des Corpus Reformatorum zielenden Bemerkung von Moss (Ovid in Renaissance France [Anm. 9], S. 85, Anm. 72) kann ich daher nur zustimmen: „Sabinus' interpretation of the Metamorphoses has been attributed to Melanchthon; [...]; there seems no real ground for this.“

11 Töppen: Die Gründung (Anm. 1), S. 263-279 (ausführliche, in der Tendenz positive Besprechung von Sabinus' Metamorphosen-Interpretation, mit stillschweigender Voraussetzung seiner Verfasserschaft).

12 Typisch für die Art der Beurteilung der Persönlichkeit des Sabinus ist z. B. die folgende Stelle bei Töppen: Die Gründung (Anm. 1), S. 143: „Melanchthon gefiel sich in der Zurückgezogenheit des scholastischen Lebens; Sabinus suchte Glanz, Ruhm und Ehre im Vordergrunde der Bühne des Lebens. Feierlicher Ernst breitete sich über alles, was Melanchthon angriff; Sabinus erfasste in allem mehr die heitere und fröhliche Seite." Dieser Tenor beherrscht auch noch die Darstellung Scheibles: Georg Sabinus (Anm. 1) (s. hier z. B. besonders S. 17 u. 22). Zu dem eher negativen Persönlichkeitsbild, das von Sabinus in der Forschungsliteratur gezeichnet wird, hat in starkem Maße der unglückliche Verlauf seiner Ehe mit Melanchthons Tochter Anna beigetragen. 
Kein Zweifel kann jedenfalls daran bestehen, daß sowohl die MetamorphosenInterpretationen als auch ,De carminibus [...] artificiose componendis praecepta“ aussagekräftige Dokumente der Lehrtätigkeit des Sabinus sind. Von dieser finden sich auch Spuren in seinen ,Poemata', und zwar in Gestalt von vier versifizierten Vorlesungsankündigungen. Mit deren einer, einem Epigramm von fünf Distichen, kündigt Sabinus für das bevorstehende Semester Vorlesungen über Ciceros Philippische Reden und Ovids Metamorphosen an. ${ }^{13}$ Obwohl das Gedicht nicht datiert ist, gehört es zweifellos in die Königsberger Zeit: Hinsichtlich Ovids dürfte dies eine der Vorlesungen sein, aus denen die ,Fabularum Ovidii interpretatio“ hervorgegangen ist, und was Cicero angeht, so wissen wir aus einer Mitteilung Töppens, daß es zu seiner Zeit, also um die Mitte des 19. Jahrhunderts, in Königsberg noch ein Autograph mit Notizen des Sabinus zu seinen Erläuterungen der 1. Philippischen Rede gegeben hat. ${ }^{14}$ Ebenfalls in die Königsberger Zeit scheint ein Gedicht von 24 Hendekasyllaben zu gehören, mit dem Sabinus eine Vorlesung über Ciceros ,Orator' ankündigt, ${ }^{15}$ denn 1546 ließ er in Königsberg eine mit einer „Praefatio de argumento huius libri et utilitate“ versehene Ausgabe dieses Textes als Grundlage für seine Vorlesung erscheinen. ${ }^{16}$ Eine dritte Vorlesungsankündigung in Gedichtform, Ovids Heroides betreffend, ${ }^{17}$ gehört eindeutig in die Zeit vor oder nach dem Wirken des Sabinus in Königsberg, also nach Frankfurt an der Oder, da ganz am Anfang auf eine am Ufer der Oder gelegene Akademie als Ort der Lehrveranstaltung hingewiesen wird. Ob die vierte versifizierte Vorlesungsankündigung in des Sabinus ,Poemata', zu Ciceros ,De legibus‘ und seinen Catilinarischen Reden, ${ }^{18}$ in die Frankfurter oder in die Königsberger Zeit gehört, ist nach gegenwärtigem Informationsstand nicht zu entscheiden.

13 Georgius Sabinus: Poëmata [...] et numero librorum et aliis additis aucta et emendatius denuo edita [Hg.: Eusebius Menius]. [Leipzig]: in officina Voegeliana [1563], S. 286 („In Philippicas Ciceronis er Ovidii libros Metamorphoseôn“).

14 Töppen: Die Gründung (Anm. 1), S. 279.

15 Sabinus: Poëmata (Anm. 13), S. 321 („In Oratorem Ciceronis“).

16 M. T. Cicero: Ad Brutum orator. G. Sabini praefatio de argumento huius libri et utilitate. Anno 1546 mense Maio. [Kolophon:] In Academia Regiimontis excudebat Iohannes Weinreich. - Titelangabe nach Töppen: Die Gründung (Anm. 1), S. 5, Nr. 17. Einen Standortnachweis für eine deutsche oder ausländische Bibliothek vermag ich nicht zu geben. Töppen muß aber ein Exemplar in der Hand gehabt haben, denn er schreibt (ebd., S. 279): „Die Ausgabe des Redners von Cicero ist nur ein Textesabdruck, den Sabinus hier in Königsberg für seine Vorlesungen veranstaltete.“ 17 Sabinus: Poëmata (Anm. 13), S. 319-321 („In Heroidas Ovidii“).

18 Ebd., S. 337-339 („In libros de legibus et orationes Catilinarias Marci Tullii Ciceronis“). 


\section{Die Metamorphosen-Interpretation}

\section{Erläuterung der Zielsetzung in Widmung und Vorwort}

Sabinus gab das Manuskript seiner Metamorphosen-Interpretation 1554 in Wittenberg in Druck. ${ }^{19}$ Ungefähr ein Jahr später verließ er die Universität Königsberg aufgrund religiöser Differenzen mit seinem Landesherrn, Herzog Albrecht von Preußen, im Gefolge des Osiandrischen Streits und kehrte an seine frühere Wirkungsstätte, die Universität Frankfurt an der Oder, zurück. Die auf den 13. Juni 1554 datierte Widmung an Herzog Albrecht könnte, wie Töppen vermutete, ein Versuch gewesen sein, diesen ,günstiger zu stimmen und gleichsam zu einiger Nachsicht zu zwingen“. ${ }^{20}$ Wie der abschließende Passus, mit dem Sabinus die Dedikation an den Herzog explizit begründet, deutlich erkennen läßt, ging es ihm mit der Publikation seiner Ovid-Interpretation offenbar hauptsächlich darum, Vorwürfen entgegenzutreten, die auf die Qualität seiner Lehrtätigkeit zielten. Er schreibt nämlich:21

Ideò verò, Illustrissime Princeps, in hac editione ad Celsi<tudinem $>\mathrm{T}<$ uam $>$ scripsi, ut specimen ostendam, unde iudicari posset de meo consilio in docendo et de diligentia mea, quam et Celsitudini tuae et omnibus prudentibus et honestis semper probari volui, ac me et haec nostra studia Tuae Celsitudini reverenter commendo. ${ }^{22}$

[Ich habe aber, durchlauchtigster Fürst, in vorliegender Publikation Deiner Hoheit deshalb geschrieben, um ein Musterbeispiel vorzuführen, von dem her die Grundtendenz meiner Lehrtätigkeit beurteilt werden kann, auch meine Gewissenhaftigkeit, an deren positiver Beurteilung durch Deine Hoheit und alle einsichtigen und ehrenwerten Persönlichkeiten mir allzeit gelegen war. Und so empfehle ich mich und diese meine Studien Deiner Hoheit mit Ehrerbietung.]

Unmittelbar davor erläutert er die äußeren Umstände und eher praktischen Erwägungen, die zur Publikation seines Werkes geführt hätten:

19 Dies geht aus dem Datum der Widmung an Herzog Albrecht (13. Juni 1554) hervor. Das Werk erschien dann 1555 bei Georg Rhaus Erben. In älteren Bibliographien wird 1554 als Erscheinungsjahr der Editio princeps angegeben (Näheres hierzu s. Editionsbericht, S. 359, Anm. 1).

20 Töppen: Die Gründung (Anm. 1), S. 222.

21 Verweise auf die Metamorphosen-Auslegung erfolgen mit Angabe des Buches (in römischen Ziffern), gefolgt von Kapitel- und ggf. Zeilenzahl unserer Ausgabe (in arabischen Ziffern). Auf den Widmungsbrief wird mit dem Kürzel D und der Zeilenzahl verwiesen.

22 D 83-87. 


\begin{abstract}
Quanquàm autem hae nostrae interpretationes non sunt omnes à me accuratè scriptae, pleraeque etiam obiter in schola tantum commemoratae et ab auditoribus avidè exceptae sunt, tamen, quia iam in multorum manibus circumferebantur, ne qui aliena assuerent, edi eas passus sum. ${ }^{23}$
\end{abstract}

[Obwohl aber diese unsere Auslegungen von mir nicht durchweg in sorgfältig ausgearbeiteter Form geschrieben worden sind, sehr vieles in der Schule auch nur beiläufig erwähnt und von den Hörern begierig nachgeschrieben wurde, habe ich dennoch, weil sie schon in den Händen vieler herumgegangen waren, ihre Veröffentlichung zugelassen, damit nicht irgend jemand nicht Dazugehöriges anflickte.]

D. h. also, daß dem Manuskript der Satzvorlage eine von Sabinus allenfalls einer letzten Durchsicht unterzogene Vorlesungsnachschrift zugrunde gelegen haben muß. Die Formulierung ,hae nostrae interpretationes non sunt omnes à me accuratè scriptae“ ist zweideutig. Sie kann besagen, daß Sabinus in seinen Vorlesungen nicht alle Sagen mit der gleichen Ausführlichkeit behandelt habe und sich dies auch in der verwendeten Nachschrift bemerkbar mache. Ich halte diese Deutung für wahrscheinlicher als die andere, die der Wortlaut ebenso zuließe: daß nämlich Sabinus einige Auslegungen von Verwandlungsgeschichten in seinen Vorlesungen nur beiläufig erwähnt habe und deren ausführlichere Ausarbeitungen, wie sie jetzt in der Publikation vorlägen, von fremder Hand, also wohl von der eines seiner Hörer, stammten.

Der Hauptteil der Widmung besteht aus einer ausführlichen Begründung der Wahl des Stoffes und der Darlegung der Methodik der Interpretation und ihres didaktischen Nutzwertes. Sabinus beginnt mit dem Hinweis auf eine Stelle in den Argonautica von Apollonius Rhodius, der man entnehmen könne, „daß die Poesie in alter Zeit die Lehre von dem Ablauf aller Zeitalter, die Darstellung der Geschichte der Welt und der bedeutendsten Veränderungen innerhalb der wichtigsten Königreiche gewesen sei und daß in die Geschichtsdarstellung eingewoben gewesen sei die Lehre von Gott, von der Gerechtigkeit und den Bestrafungen des Unrechts“ (,veterem poëticam fuisse doctrinam de serie omnium temporum et historiam mundi et maximarum mutationum in praecipuis regnis, et historiae intextam fuisse doctrinam de Deo, de iusticia et de poenis iniusticiae“). ${ }^{24} \mathrm{Da}$ die Kenntnis des Geschichtsverlaufs, soweit man ihn kennen könne, von Nutzen sei, habe Ovid mit den Metamorphosen die Absicht verfolgt, die Darstellung der Weltgeschichte bis zu seiner eigenen Zeit fortzuführen; das Werk sei daher

23 D 80-83.

24 D 9-11. 
gewissermaßen ein „chronicon“. ${ }^{25}$ Obwohl er, Sabinus, den jungen Leuten dieses Werk „wegen der lateinischen Sprache und der Art der Verse“ („propter linguam Latinam et genus versuum“ $)^{26}$ vorlege, gestalte sich doch die Lektüre angenehmer, wenn man dabei auch seine Gedanken den Absichten des Dichters, den behandelten Sachgegenständen und dem Geschichtsverlauf zuwende. Die historische Perspektive sei auch deshalb von besonderem Nutzen, weil man aus dem Vergleich der Geschichtsschreibung der alten Griechen mit der Lehre der Kirche über den Gang der Geschichte die Wahrheit letzterer erkenne und sie so um so mehr lieben lerne. Die hier gelieferten Interpretationen der Geschichten Ovids seien teils historisch, teils moralisch ausgerichtet, weil das Altertum beides auf vielerlei Gebieten miteinander vermischt habe. Die Möglichkeit, an einzelnen Sagenkomplexen historische mit moralischer Interpretation zu verbinden, exemplifiziert Sabinus an den Kyklopen, an Bellerophontes und an Orion.

Mögen solche Interpretationen, so fährt Sabinus fort, auch nicht gleichermaßen stimmig sein, so sind sie doch für die jungen Leute nützlich, vorausgesetzt, daß man klug und differenziert zu Werke geht, daß man keine ungereimten, naturwidrigen oder weithergeholten Auslegungen ersinnt und nicht Heiliges mit Profanem vermengt, sondern die Absichten der Autoren im Auge behält, die spezifischen Quellen der einzelnen Stoffe in Betracht zieht und ihrer Nutzanwendung bestimmte Grenzen setzt. Solche Sorgfalt bei der Suche nach gut passenden und der Vermeidung naturwidriger Bezugnahmen und bei der Einhaltung des rechten Maßes kann für die Schulung der Urteilsfähigkeit der jungen Leute großen Nutzen bringen. Wenn sie sich nämlich an eine solche Schulung gewöhnt haben, werden sie später um so mehr Umsicht walten lassen bei der Auslegung der Lehre der Kirche und keine Spielereien mit unangemessenen, abgeschmackten und absurden Allegorien betreiben, wie es einst Origenes und die Mönche getan hätten, die unterschiedslos alle Stoffe in ganz beliebige Figuren gekleidet hätten. So gefährlich aber eine derartige Willkür sei, so könnten doch kunstgerechte Allegorien, am rechten Ort angewandt, einen wichtigen und angenehmen Zierat bilden und auch als Gedächtnisstützen dienen.

Eine weitere, ausführlichere und differenziertere Erläuterung der Grundsätze seiner Ovid-Interpretation bietet Sabinus in der Einführung, die den Interpretationen zum 1. Buch der Metamorphosen vorangestellt ist. Diese beginnt mit der Feststellung einer grundsätzlichen Identität von Dichtung und Philosophie:

25 D 29.

26 D 20. 
Poetica nihil aliud est nisi philosophia numeris et fabulis concinna, qua honestarum artium doctrina et praecepta de moribus illustrata regnorum exemplis continentur. ${ }^{27}$

[Die Poesie ist nichts anderes als eine durch Versmaße und dichterische Erfindungen gefällig gestaltete Philosophie, in der die Lehre ehrbarer Künste und Moralvorschriften, erhellt durch Beispiele von Königreichen, enthalten sind.]

Wie nämlich Cicero in den Tusculanen bezeuge, waren in der Frühzeit des griechischen Altertums die Dichter die ersten Gelehrten. Diese hätten, um die Menschen ihren Belehrungen zugänglich zu machen, zwei Lockmittel benutzt: die Süßigkeit der Verse und die Erfindung von Geschichten. Dies meine Horaz, wenn er sage (Ars poet. 333): „Et prodesse volunt et delectare poetae.“ Da also die Dichtung dieselbe Lehre verkünde wie die Philosophie, steckten die Geschichten der Dichter zweifellos voller Weisheit und Gelehrsamkeit - seien sie doch von Menschen ersonnen, die ihr ganzes Streben auf Wissenserwerb und Weisheit ausgerichtet hätten. Wie nämlich an Weinstöcken die schönsten und süßesten Trauben unter dem Weinlaub verborgen seien, so seien in der Poesie die nützlichsten Dinge mit den Hüllen von Erdichtungen bedeckt, und es gebe so gut wie keine alte poetische Erfindung, die nicht etwas enthalte, was aus der Geschichte, der Naturkunde oder der Moralphilosophie entlehnt sei. Deshalb habe Erasmus zu Recht gesagt, die Poesie sei ein Kuchen, angefüllt mit Köstlichkeiten aus Wissenschaften jeder Art (,poëticam esse placentam deliciis conditam ex omni disciplinarum genere"). ${ }^{28}$

Ovids Metamorphosen-Werk enthalte gleichsam gebündelt eine hervorragende Auswahl von Erfindungen aller Dichter, in denen anschauliche Beispiele göttlichen Wohlwollens und Zorns und anschauliche Bilder des ganzen Menschenlebens und seiner Beschaffenheit vorgeführt würden. Der Autor verfolge dabei den Verlauf der Geschichte vom Anfang der Welt bis zu seiner eigenen Zeit und lehre damit, daß nichts im Menschenleben zufällig geschehe, sondern daß alles von Gott gelenkt werde. Die göttliche Lenkung der Welt begünstige fromme und ehrbare Handlungen, bestrafe aber Verbrechen mit verschiedenen Lebenskatastrophen, ganz besonders aber die Verachtung der Religion, die oft die Vernichtung ganzer Völker, Städte und Geschlechter durch Krieg, Pestilenz und andere

\section{I,1, 3-5.}

28 I,1, 21-22. - Das Erasmus-Zitat ist aus Buch 2 des Werkes ,Ecclesiastes, sive De ratione concionandi'; es lautet in wörtlicher Wiedergabe: „Siquidem vera poesis nihil aliud est quam ex omnium disciplinarum delitiis ac medullis condita placenta aut, ut melius dicam, ex electissimis quibusque flosculis compositum mellificium." (Desiderius Erasmus Roterodamus: Opera omnia V-4. Amsterdam 1991, S. 258, Z. 260-263). 
schwerste Übel zur Folge hätte. Außer solchen der Geschichte entnommenen Lebensexempeln enthielten Ovids Metamorphosen eine solche Fülle von astronomischem und naturkundlichem Wissen, so viele Namen und Beschreibungen von Regionen, Ortschaften, Städten, Bergen und Flüssen, daß man an ihm zu einem großen Teil Geographie, Astronomie und Naturlehre studieren könne. ${ }^{29}$ Ovids Dichtung sei somit nicht nur zu oberflächlicher Unterhaltung bestimmt, sondern stelle einen Schatz der Gelehrsamkeit dar, dessen Lektüre erstens zur rechten Lebensführung anleite, indem uns seine Exempla zur Tugend einlüden und von der Schlechtigkeit abrieten, und uns zweitens in eine Vielzahl von Wissensgebieten einführe. Darüber hinaus biete das Werk noch anderweitigen Nutzen, vor allem aber den, daß es die Studenten der Beredsamkeit in das vollständige System der Redekunst einführe. Es sei ein vollkommenes Muster einer kunstgerechten Disposition auch der disparatesten Ergebnisse der Inventio in verschiedenen Themenfeldern und Stoffgebieten; es demonstriere, wie Gegenstände durchsichtig, wortreich und gefällig dargestellt werden könnten. Bewundernswert sei seine Mannigfaltigkeit an Figuren, Affektdarstellungen und Sentenzen.

\section{Inhalte und Aspekte der Metamorphosen-Interpretation}

Sabinus bietet in seiner Interpretatio keine Vers-zu-Vers-Kommentierung, sondern bespricht nach und nach, in der Reihenfolge der einzelnen Bücher der Metamorphosen, die darin enthaltenen Episoden, aber auch spezifische Einzelaussagen bestimmter Versgruppen oder Einzelverse unter Aspekten, die ihm von Fall zu Fall vorrangig erscheinen. Intensität und Ausführlichkeit der Einzelbesprechungen können sehr unterschiedlich sein. Manche Sagenstoffe werden auf mehreren Druckseiten abgehandelt (z. B. die Geschichte Phaethons: II,1), manche auch nur eines einzigen Satzes gewürdigt (z. B. die Verwandlung der Aglauros in einen Stein: II,17). Der Originaltext selbst wird nicht mitabgedruckt, die parallele Benutzung einer Textausgabe also vorausgesetzt. Oft wird aber ein expliziter Textbezug hergestellt durch Zitation eines oder zweier Verse am Anfang einer Einzelinterpretation, in die zuweilen zur Illustration bestimmter Auslegungen auch hin und wieder längere Textpassagen eingebaut werden.

29 Ähnlich wurde auch das Studium der Werke Vergils begründet. Siehe dazu meinen Aufsatz über die Vorlesungsankündigungen zu Vergils „Aeneis“ von dem Sabinus-Schüler Johannes Bocer: Lothar Mundt: Johannes Bocers Ankündigungen von Aeneis-Vorlesungen an der Universität Rostock 1560-1563. Ein Beitrag zur akademischen Vergil-Rezeption im 16. Jahrhundert. In: Wolfenbütteler Renaissance-Mitteilungen 25 (2001), S. 103-121. 
Sehr oft beruft sich Sabinus für einzelne Auslegungen auf Autoritäten und Gewährsleute, neben antiken Autoren und Kirchenvätern vor allem - was im Hinblick auf seinen Bildungsgang nicht verwunderlich ist - auf italienische Humanisten. Von diesen nennt er besonders häufig Iovianus Pontanus, des weiteren, in der Reihenfolge ihrer ersten Nennung und in verschiedenen Zusammenhängen, Iacobus Sadoletus, Angelus Polizianus, Petrus Gravina, Laurentius Valla, Caelius Calcagninus, Petrus Bembus, Hieronymus Cardanus, Lazarus Bonamicus (bei ihm hat Sabinus, wie er in X,8 mitteilt, in Italien Vorlesungen gehört), Giovanni Boccaccio, Baptista Mantuanus, Claudius Marius Aretius, Marcellus Palingenius. Oft wird auf Erasmus von Rotterdam Bezug genommen. Von deutschen Gelehrten des 16. Jahrhunderts werden nur wenige und diese meist auch nur vereinzelt angeführt. Alle gehören dem engeren Umfeld des Autors an; es sind, ebenfalls in der Reihenfolge ihrer ersten Nennung: Joachim Camerarius, Johannes Dantiscus, Vitus Winshemius, Philipp Melanchthon und Martin Luther.

Die einzelnen Sagenkomplexe werden, wie in der Einführung angekündigt, moralisch, historisch und naturkundlich gedeutet, wobei manchmal nur einer dieser drei Deutungsaspekte zur Geltung kommt, oft aber zwei oder auch alle drei, wie es sich von den Deutungstraditionen jeder Sagenepisode gerade anbot, miteinander kombiniert werden.

In Sabinus' Darstellung dominiert eindeutig die für das Literaturverständnis des 16. Jahrhunderts ohnehin wesentliche, zudem von seinen Vorläufern in der Metamorphosen-Interpretation bereits intensiv ausgearbeitete moralische Auslegung. Für sie möchte ich aus der großen Fülle einige markante Beispiele anführen. Daß Pallas bewaffnet sei, bedeute, daß Weisheit ohne Macht nichts wert sei - und vice versa (II,15). Das schlimme Ende der Beziehung von Jason und Medea beweise, daß auf einer Ehe, die gegen den Willen der Eltern geschlossen werde, kein Segen ruhe (VII,13), ebenso wie auch der Tod von Pyramus und Thisbe eine Strafe für den Ungehorsam gegenüber ihren Eltern sei (IV,6). Jupiters Erfolg als Goldregen bei Danae belege, daß sich mit Gold jeder Widerstand überwinden lasse (IV,24). Pygmalions Geschichte lehre, daß eine züchtige Frau von Gott gegeben werde und von ihm zu erbitten sei (X,11). Die Gorgonen seien zu deuten als Wollüste und Reize, durch die dumme Menschen gleichsam in Steine verwandelt würden; sie seien zu besiegen mit dem Schild der Pallas und dem Schwert Merkurs, d.h. mit Klugheit (IV,29).

Historisch von größerem Interesse sind hier die zahlreichen aktualisierenden Parallelen, die in zeitkritischer Absicht gezogen werden. So könne man in der Aussaat der Drachenzähne durch Cadmus ein Bild für die Zwietracht heutiger Fürsten und die Gefahren von Bürgerkriegen sehen (III,1). Actaeons Verwandlung in einen Hirsch zeige, daß Fürsten, die ständig der Jagdleidenschaft frönten, ihre menschliche Natur verlören (III,3). Die meisten Fürsten und Könige seien 
so ungebildet wie Midas; auf sie sei dessen Geschichte eigentlich gemünzt. Es gebe aber auch Ausnahmen wie König Salomo und Ubaldus Feretrius, Herzog von Urbino, der bereit gewesen sei, all seinen Reichtum für die Weisheit hinzugeben (XI,4). In dem Schilfrohr, das durch sein Flüstern des Midas Eselsohren verriet, könne man ein Sinnbild für die Schriftsteller sehen, die die Verfehlungen von Fürsten der Nachwelt überlieferten (XI,5). Die Auseinandersetzung zwischen Ajax und Odysseus versinnbildliche den Widerstreit von militärischen und zivilen Tugenden (arma und toga: XIII,1), der sich in neuerer Zeit fortsetze in der Verachtung der Gelehrten von Seiten des Ritterstandes, zu der Sabinus einen diesen Stand ironisierenden Ausspruch Luthers anführt (XIII,2,352-356). Die Mahnung Apollos an Paris (Met. 12,601-603), er solle im Kampf um Troja seine Pfeile nicht auf unbedeutende Griechen, Kämpfer aus dem einfachen Volk, verschwenden, sondern sich Achilles zum Ziel nehmen, könne man heutzutage als eine Mahnung an die Fürsten lesen, ihren Ruhm nicht im Hinmetzeln armer Bürger zu suchen, sondern im Kampf gegen die Türken, zum Ruhme Gottes und zur Verteidigung des Glaubens (XII,11). Die inzestuöse Liebe der Byblis zu ihrem Bruder habe eine moderne Parallele in der Liebe Papst Alexanders VI. Borgia zu seiner Tochter Lucretia (IX,22). Wie einst vor dem Tyrannen Pyreneus seien die Musen im Schmalkaldischen Krieg auf Flügeln, d.h. mit göttlicher Hilfe, aus Wittenberg und Leipzig geflohen, hätten so überlebt und später ihre alten Sitze dort wieder eingenommen (V,3). Bei derlei Aktualisierungen, in denen Fürsten- und Adelskritik besonders deutlich hervortritt, ${ }^{30}$ begibt sich Sabinus zuweilen auch auf das Feld der Literaturkritik. So habe man unter den Elstern, in die die Töchter des Pierus verwandelt wurden, einfältige und arrogante Verseschmiede und Poetaster $\mathrm{zu}$ verstehen wie z.B. Doletus (Etienne Dolet), ${ }^{31}$ der den um die Literatur hochverdienten Erasmus mit läppischen und schmutzigen Versen heimgesucht habe (V,2). In Phaethon könne man ebenso einen seine Kräfte überschätzenden Fürsten sehen (wie z. B. Ludovico Sforza, der in dem Krieg, den er aus Macht-

30 Vgl. hierzu vor allem die Kapitel XII,10 u. 11. In XII,10 verweist Sabinus bei der Besprechung des Gastmahls der Lapithen und Kentauren, mit dem Trunkenheit und daraus entspringende Gewalttätigkeit angeprangert würden, auf einen ihm bekannten zeitgenössischen Vorfall im Gebiet von Thüringen und Franken: Ritter, die zu einer Hochzeit geladen gewesen seien, hätten im Zustand der Trunkenheit zu den Waffen gegriffen und den Bräutigam mitsamt seinen Verwandten und Gevattern erschlagen. ,Centaurus‘ war in der Frühen Neuzeit ohnehin ein gern gebrauchter Spottname für ungebildete Angehörige des Adels. Gleich im nächsten Kapitel (XII,11) wirft er gar den Fürsten vor, daß sie dazu neigten, Bürgerkriege anzuzetteln und in deren Verlauf unschuldige Bürger und Bauern niederzumetzeln (die Bezugnahme auf die Ereignisse des deutschen Bauernkriegs ist unverkennbar).

31 Vgl. die gegen Doletus als Dichter gerichteten polemischen Epigramme in Sabinus' Poëmata (Anm. 13), S. $286 \mathrm{f}$. 
streben mit Hilfe der Franzosen in Italien entfacht habe, untergegangen sei) wie einen übermäßig ehrgeizigen Gelehrten, der sich an Projekte mache, die seine Kräfte überstiegen; in diesem Sinne sei Angelus Polizianus von einem Kardinal aus Pavia zurechtgewiesen worden, als er sich anheischig gemacht habe, Homer ins Lateinische zu übersetzen (II,2).

Soweit der Aspekt der moralischen Auslegung. Das Prinzip der historischen Auslegung besteht darin, daß ein Sagenstoff auf eine sehr rationalistische Weise, etwa so, wie man es noch von den Artikeln des mythologischen Lexikons von Benjamin Hederich ${ }^{32}$ kennt, auf einen aus verschiedenen Gründen sachlich verzerrt überlieferten oder auch allegorisch oder sinnbildlich verkleideten realhistorischen Gehalt zurückgeführt wird. Auch hierfür einige Beispiele: Europa wurde eigentlich nicht von dem in einen Stier verwandelten Gott Jupiter geraubt, sondern von den Kretern auf einem Schiff, auf das ein Stier gemalt war, nach Kreta, zu dessen König, der Jupiter hieß, verschleppt (II,18). - Das Goldene Vlies, das die Argonauten raubten, war eigentlich nur ein Goldschatz, denn die Gegend um Kolchis war reich an Gold. Das Motiv der Argonauten war das gleiche wie das der Spanier, die in neuerer Zeit Gold aus (West-)Indien holten (VII,5). - Ähnlich verhält es sich mit den goldenen Äpfeln im Garten des Atlas. Diese versinnbildlichen den Goldreichtum Mauretaniens, dessen König der historische Atlas war, und nichts anderes als Gier nach Gold hat tatsächlich den Besuch des Perseus bei Atlas motiviert - so wie Kaiser Karl V. durch die Spanier (west-)indisches Gold hat rauben lassen $(I V, 26)$. - Der Stier, mit dem die kretische Königin Pasiphae Unzucht getrieben haben soll, war eigentlich, wie Plutarch und Servius bezeugen, ein Liebhaber, der Taurus hieß (VIII,2). - Daß die Stadtmauern Trojas von Apollo und Neptun gebaut worden sind, ist laut Boccaccio nur eine bildliche Umschreibung dafür, daß Laomedon zu ihrer Finanzierung Gold aus den Tempeln dieser beiden Götter verwendet hat. Man kann damit auch den Brauch deutscher Städte vergleichen, beim Bau von Stadtmauern Steine von Grabmälern zerstörter Friedhöfe zu verwenden (XI,6). - Die Kyklopen waren eigentlich sizilische Räuber. Die Mär von dem einen Auge, das sie auf der Stirn trugen, wurde wahrscheinlich veranlaßt durch die Helme dieser Räuber: solche nämlich, die das Gesicht bedeckten und in Augenhöhe ein Loch zum Durchsehen hatten (XIII,11). - Virbius war nicht wirklich der wiederauferstandene Hippolytus, sondern ein Betrüger, der im Auftrag von Diana-Priestern handelte, die damit ihre Kultstätte interessant und attraktiv machen wollten. Ähnliche Betrüger gab es auch in jüngster Zeit. So wurde im Jahre 1547 in einer verfallenen Burg ein ganz verwahrloster Mann auf-

32 Benjamin Hederich: Gründliches mythologisches Lexicon [...]. Leipzig 1770, Reprint Darmstadt 1996. 
gefunden, der behauptete, er sei Kaiser Friedrich II. und werde das Reich reformieren (XV,9).

Solcherlei gewissermaßen aufklärerische historische Auslegungen nehmen aber gegenüber den moralischen eher eine Randposition ein und werden oft mit diesen verknüpft oder ihnen an die Seite gestellt, wie z. B. bei der Sage von der Errichtung der trojanischen Stadtmauer durch Neptun und Apollo, die man nicht nur als Metapher für die Finanzierung des Baus durch Tempelraub lesen müsse, sondern auch als Mahnung verstehen könne, daß sich ein mächtiges Staatswesen nur durch göttliches Wohlwollen entwickeln könne (XI,6).

Eine untergeordnete Rolle spielen ihrer Zahl nach auch die naturkundlichen Erläuterungen, von denen ich ebenfalls ein paar Beispiele anführen möchte: Die Erlegung des nach der Sintflut von der Erde hervorgebrachten Python-Drachens durch Apollo ist ein Bild für die Kraft der Sonne bei der Austrocknung des Sumpfes, den die Flut hinterlassen hatte $(\mathrm{I}, 19)$. - Daß die Behausung der Invidia als öde und kalt dargestellt wird, geht zurück auf die Lehre der Mediziner, daß Kälte des Blutes eine physiologische Voraussetzung für die Entstehung des NeidAffektes sei (II,16). - Der mit Augen übersäte Argus ist ein Bild für den gestirnten Himmel, seine Tötung durch Merkur ein Sinnbild für das Verblassen der Sterne bei Aufgang der Sonne (I,25).

Die Geschichte von Argus bietet ein schönes Beispiel für die Kombination des naturkundlichen mit dem moralischen Deutungsaspekt. Wendet man letzteren an, so vermittelt die Tötung des Argus durch Apollo die Lehre, daß auch ein sehr umsichtiger Mensch durch verschlagene Beredsamkeit übertölpelt werden könne. Diese Art von Beredsamkeit verkörpere Merkur, dessen Flügelschuhe zudem ein Sinnbild der Beweglichkeit (,volubilitas') der Zunge eines guten Redners seien, während sein Zauberstab die Gewalt der Beredsamkeit repräsentiere, die die Geister der Menschen anlocke und antreibe (I,25,489-493).

Der hiermit angesprochene rhetorisch-sprachliche Deutungsaspekt der Ankündigung, in Sabinus' Einführung der vierte nach den drei bereits besprochenen, bildet innerhalb der großen Masse der Interpretationen nur einen kleinen Teil. An einzelnen Stellen wird er allerdings relativ breit abgehandelt: mit Paraphrasen und rhetorischen Analysen der Streitreden von Ajax und Odysseus (XIII,1/2), der Klagen Hecubas (XIII,7) und der Argumente, mit denen sich Medea in ihren Überlegungen für Jason entscheidet (VII,4). Im allgemeinen aber erschöpft sich die Behandlung dieser Thematik in gelegentlichen Nebenbemerkungen wie den folgenden: Bei der Beschreibung der Sintflut im ersten Buch der Metamorphosen habe Ovid Techniken der ,amplificationes, prosopopoeiae, et hypotyposes poeticae“ (I,12,331-332) angewandt. - Die Schilderung, die Ovid von dem abstoßenden Äußeren der Invidia gebe, leite sich her „ab effectu“ (II,16,265). - In dem gegenüber Merkur treubrüchigen Hirten Battus habe Ovid einen schlech- 
ten Dichter bloßstellen wollen, indem er ihm Verse mit lästigen Wortwiederholungen in den Mund gelegt habe (Met. 2,702-705). Hintergrund dieser Deutung ist die Verbindung des Hirtennnamens Battus mit dem griechischen Begriff der $\beta \alpha \tau \tau$ خоyí $\alpha$, d. h. ,Geplapper‘ (II,14). - Die beiden Schwestern Progne und Philomela, die in eine Schwalbe und eine Nachtigall verwandelt wurden, könne man mit Laurentius Valla als Sinnbilder der miteinander verschwisterten Disziplinen Rhetorik und Poesie verstehen. Da die Schwalbe (Progne) eher in Häusern und Städten heimisch sei, könne man sie mit der urbanen Beredsamkeit, z. B. mit der Gerichtsrede, vergleichen, wohingegen die Nachtigall (Philomela), die ebenso wie die Dichter eine Vorliebe für einsame Waldgegenden habe, die ländliche Rede und die Poesie repräsentiere. Wie aber die Nachtigall schöner singe als die Schwalbe, so sei auch die Poesie der Redekunst überlegen (VI,13,260-262). - Mit Gregor von Nazianz könne man in der drei Tieren, vorn einem Löwen, hinten einer Schlange, in der Mitte einer Ziege gleichenden Chimaera eine Allegorie auf die drei Redegenera sehen (IX,23,321-325).

Damit sind alle wesentlichen Elemente des Metamorphosen-Buches von Sabinus beschrieben. Es soll aber noch auf eine Eigenheit hingewiesen werden, die Sabinus mit seinem Lehrer Melanchthon teilt: die Gepflogenheit, in den Vorlesungstext diverse Anekdoten einzustreuen, die ein kulturhistorisch nicht uninteressantes Element der Ovid-Interpretationen darstellen. ${ }^{33}$ So erzählt Sabinus anläßlich der Schilderung des Werwolfs (Met. 7,270f.) von einem verwildert aussehenden Mann, den preußische Bauern gefangen und zu Herzog Albrecht gebracht hätten. Dieser Mann habe von sich behauptet, daß er sich zweimal im Jahr, zu Weihnachten und am Tage Johannes des Täufers, in einen Wolf verwandle. Als man ihn daraufhin für längere Zeit gefangen hielt, erwies sich diese Behauptung als nichtig; es trat keine Verwandlung ein. Dieser Vorfall beweise, daß umlaufende Geschichten von Werwölfen bloße Hirngespinste seien (VII,7). - Ähnlich sei die Erzählung von dem Jungbrunnen zu bewerten, die kürzlich in Nürnberg in deutschen Versen („rythmis Germanicis“) herausgegeben worden sei, ${ }^{34}$ nämlich als völlig unglaubwürdig. Es habe auch einmal einen Betrüger gegeben, der sich anhei-

33 Eine große Sammlung von Anekdoten aus Melanchthons Vorlesungen, betitelt ,Historiae quaedam recitatae a Philippo Melanthone inter publicas lectiones', ist nach der Handschrift seines Schülers Wericus Vendenhaimerus abgedruckt in: CR 20 (1854), Sp. 519-608.

34 Es handelt sich gewiß um den 1548 entstandenen Schwank ,Der jünckprünen“ von Hans Sachs, in: Hans Sachs: Sämtliche Fabeln und Schwänke. In chronologischer Ordnung nach den Originalen hg. von Edmund Goetze. 2. Aufl. besorgt von Hans Lothar Markschies. Bd. 1. Halle a. d. S. 1953 (Neudrucke deutscher Literaturwerke des XVI. u. XVII. Jahrhunderts 110-117), S. 321323. 
schig gemacht habe, Herzog Karl von Geldern, der schon ein hinfälliger Greis war, durch trinkbares Gold so zu verjüngen, daß er wie ein Vierzigjähriger ausgesehen hätte. Die Geschichte von der Verjüngung des Aeson durch Medea, die Sabinus auf dieses Thema gebracht hat, müsse deshalb aber nicht ganz falsch sein. Man könne sie für eine poetische Übertreibung eines glaubwürdigen Geschehens halten: daß nämlich die arzneikundige Medea mit einem Medikament das Leben von Jasons Vater verlängert habe (VII,8). - Wie die Thebaner von einem nicht dingfest zu machenden Feind behelligt worden seien, der von Ovid (Met. 7,757793) bildlich als der teumessische Fuchs eingeführt werde, so sei Sachsen sieben Jahre lang von einem märkischen Straßenräuber namens Lepus (Hase) heimgesucht worden (VII,18). Gemeint ist der 1540 in Berlin hingerichtete Hans Kohlhase, das historische Vorbild von Kleists ,Michael Kohlhaas‘. - Zu einem Passus in Ovids Schilderung der Pest auf Aegina, in dem berichtet wird, daß pestkranke Stiere, die am Altar des Jupiter-Tempels geopfert worden waren, kaum Blut in sich gehabt hätten (Met. 7,599), merkt Sabinus an, daß er im Jahre 1549, als in Preußen eine entsetzliche Pest grassierte, der Enthauptung einer Frau beigewohnt habe, aus deren Körper gerade soviel Blut geflossen sei, wie in eine hohle Hand gehe. Dies sei eine Bestätigung der auch von Vergil in den Georgica erwähnten Beobachtung, daß Pestkranke nur wenig Blut in sich hätten (VII,15,301-305). - So wie Herkules den oft Überschwemmungen verursachenden Fluß Achelous mit dem Bau von Dämmen bändigte (dies sei der eigentliche Sinn der Sage von dem Sieg des Herkules im Ringkampf mit dem Flußgott), so hätten die Einwohner des preußischen Marienburg die Überschwemmungen der Weichsel beendet, indem sie ihr eine zweite Mündung anlegten und an ihren Ufern Dämme aufschütteten (IX,2). - Im Zusammenhang der Geschichte von dem Ursprung der Feindschaft zwischen Pygmäen und Kranichen (Met. 6,90-92) berichtet Sabinus von einem nur eine Elle großen Mann, den man kürzlich in Italien in einem Papageienkäfig herumgetragen habe; Hieronymus Cardanus erwähne ihn in seinen Schriften $(\mathrm{VI}, 4)$.

\section{Des Sabinus Standort in der Tradition der Metamorphosen-Kommentierung}

Eine Beschreibung der Position, die des Sabinus Werk - Bestandteil einer schon zur Zeit seines Erscheinens regen humanistischen Mythographie ${ }^{35}$ - innerhalb

35 Siehe hierzu die wichtige, stoff- und aspektreiche Übersichtsdarstellung von Jörg Jochen Berns: Mythographie und Mythenkritik in der Frühen Neuzeit. Unter besonderer Berücksichtigung des deutschsprachigen Raumes. In: Herbert Jaumann (Hg.): Diskurse der Gelehrtenkultur 
der Ovid-Interpretation seit dem Ausgang des Mittelalters einnimmt, ist in den 80er und 90er Jahren des vergangenen Jahrhunderts von Ann Moss in zwei die Zusammenhänge gründlich analysierenden Arbeiten $^{36}$ bereits geliefert worden, so daß ich mich, auf diese gestützt, mit einigen knapp zusammenfassenden Bemerkungen begnügen kann. Mit der Auffächerung seiner Interpretation in die

in der Frühen Neuzeit. Ein Handbuch. Berlin, New York 2011, S. 85-154; dazu auch: ders.: Mythos / Mythologie. In: Renaissance-Humanismus. Lexikon zur Antike-Rezeption. Hg. von Manfred Landfester. Stuttgart, Weimar 2014 (Der Neue Pauly. Supplemente 9), Sp. 657-670; Bernhard Kreuz, Petra Aigner u. Christine Harrauer: Bibliographie zum Nachleben des antiken Mythos. Version 26. 07. 2012: https://de.scribd.com/document/259323557/Bibliographie-zumNachleben-[...]. - Ein Kernwerk dieses Stoffgebietes der Literatur der Frühen Neuzeit ist des italienischen Humanisten Natalis Comes, eigtl. Natale Conti (1520-1582), erstmals Venedig 1551, also wenige Jahre vor der Metamorphosen-Auslegung des Sabinus, erschienene und oft nachgedruckte ,Mythologia‘. Neuausgabe als Reprint eines Nachdrucks von 1616: Natale Conti: Mythologiae; M. Antonio Tritonio: Mythologia. Padua 1616. Introductory notes by Stephen Orgel. New York, London 1979 (The Philosophy of Images 13).

36 S. o., Anm. 9. Zur wissenschaftlichen und literarischen Rezeption von Ovids Metamorphosen in der Frühen Neuzeit siehe aber auch: Maria Moog-Grünewald: Metamorphosen der $\mathrm{Me}$ tamorphosen. Rezeptionsarten der ovidischen Verwandlungsgeschichten in Italien und Frankreich im XVI. und XVII. Jahrhundert. Heidelberg 1979 (Studien zum Fortwirken der Antike 10); Peter E. Knox: Commenting on Ovid. In: A companion to Ovid. Ed. by Peter E. Knox. Chichester 2009, S. 327-340, hier S. 333-338; J. Engels: Les commentaires d'Ovide au XVI' siècle. In: Vivarium 12 (1974), Heft 1, S. 3-13; Bodo Guthmüller: Lateinische und volkssprachliche Kommentare zu Ovids „Metamorphosen“. In: Der Kommentar in der Renaissance. Hg. von August Buck und Otto Herding. Boppard 1975 (Kommission für Humanismusforschung. Mitteilung 1), S. 119-139; ders.: Picta Poesis Ovidiana. In: Renatae litterae. Studien zum Nachleben der Antike und zur europäischen Renaissance. August Buck zum 60. Geburtstag [...]. Hg. von Klaus Heitmann und Eckhart Schroeder. Frankfurt a. M. 1971, S. 171-192; ders.: Ovidio Metamorpheseos Vulgare. Formen und Funktionen der volkssprachlichen Wiedergabe klassischer Dichtung in der italienischen Renaissance. Boppard 1981 (Veröffentlichungen zur Humanismusforschung 3); Die Rezeption der Metamorphosen des Ovid in der Neuzeit. Der antike Mythos in Text und Bild. Internationales Symposion der Werner-Reimers-Stiftung (22. bis 25. April 1991). Hg. von Hermann Walter u. Hans-Jürgen Horn. Berlin 1995 (Ikonographische Repertorien zur Rezeption des antiken Mythos in Europa. Beihefte 1); Ovidian transformations. Essays on Ovid's Metamorphoses and its reception. Ed. by Philip Hardie [u. a.]. Cambridge 1999; Raphael Lyne: Ovid's changing worlds. English Metamorphoses, 1567-1632. Oxford 2001 (zu englischen Übersetzungen der Metamorphosen in diesem Zeitraum); H. David Brumble: Classical myths and legends in the middle ages and the renaissance. A dictionary of allegorical meanings. London, Chicago 1998; Gerlinde HuberRebenich: Ovids Göttersagen in illustrierten Ausgaben des 15. und 16. Jahrhunderts. In: Wechselseitige Wahrnehmung der Religionen im Spätmittelalter und in der Frühen Neuzeit. Bd. 2: Kulturelle Konkretionen (Literatur, Mythographie, Wissenschaft und Kunst). Hg. von Ludger Grenzmann u. a. Berlin, Boston 2012 (Abhandlungen der Akademie der Wissenschaften zu Göttingen, N.F. 4), S. 185-207. 
genannten drei Deutungsaspekte, deren Wurzeln in die Antike zurückreichen, ${ }^{37}$ steht Sabinus, rein formal gesehen, immer noch in einer Tradition der Metamorphosen-Kommentierung, die im 14. Jahrhundert von dem französischen Benediktiner Petrus Berchorius (eigentlich Pierre Bersuire, 1290[?]-1362) begründet worden war. Berchorius wendet in seinem 1340 geschriebenen und erstmals 1509 in Paris unter falschem Namen (dem des englischen Dominikaners Thomas Walleys) gedruckten ,Ovidius moralizatus، ${ }^{38}$ eigentlich Kapitel 2-15 von Buch 15 des enzyklopädischen ,Reductorium morale‘, den aus der Bibelexegese bekannten vierfachen Schriftsinn auf die Auslegung der Metamorphosen an, indem er hier ebenfalls vier Arten der Textauslegung ansetzt: eine naturkundliche, eine historische, eine moralische oder tropologische und eine allegorische oder geistliche. Das bei seiner Drucklegung wegen seiner noch ganz dem Mittelalter verhafteten Methodik der verchristlichenden Allegorisierung heidnischer Mythen schon anachronistische Werk wurde in dem sechs Jahre später (1515) erschienenen ersten Teil der Dunkelmännerbriefe (Brief 28, von Conradus Dollenkopffius an Ortvinus Gratius) ${ }^{39}$ aus der Sicht des Renaissance-Humanismus heftig verspottet.

Den Beginn einer Auslegung von Ovids Metamorphosen aus humanistischem Geist markiert der 1493 in Venedig erschienene Kommentar des italienischen Philologen Raphael Regius (eigtl. Raffaelo Reggio, ca. 1440-1520). ${ }^{40}$ Dieser ver-

37 Die schon klassische Untersuchung hierzu bietet das erstmals London 1940 in französischer Sprache erschienene Werk von Jean Seznec: Das Fortleben der antiken Götter. Die mythologische Tradition im Humanismus und in der Kunst der Renaissance. Aus dem Französischen von Heinz Jatho. München 1990. Hiernach ist die historische Deutungstradition auf Euhemeros (4./3. Jh. v. Chr.) zurückzuführen, der in den antiken Göttern überhöhende Darstellungen von bedeutenden Herrschern sah (ebd., S. 13-15), die naturwissenschaftliche auf die antike Astronomie und Astrologie mit ihrer Gleichsetzung von Sternen und Sternbildern mit Göttergestalten (ebd., S. 31-35), die moralische schließlich auf die Stoiker (ebd., S. 65-67).

38 Wissenschaftliche Ausgabe: Petrus Berchorius: Reductorium morale, liber XV: De formis figurisque deorum / Ovidius moralizatus. Naar de Parijse druk van 1509. [...]. [Ed. Jean Engels]. Utrecht 1960-1962 (Werkmateriaal [1]-2). - Beschreibung und Analyse des Kommentars von Berchorius bei Moss: Ovid in Renaissance France (Anm. 9), S. 23-26; dies. (Hg.): Latin commentaries on Ovid from the Renaissance (Anm. 9), S. 61-101; Paul Michel: Vel dic quod Phebus significat dyabolum. Zur Ovid-Auslegung des Petrus Berchorius. In: ders., Hans Weder (Hgg.): Sinnvermittlung. Studien zur Geschichte von Exegese und Hermeneutik I. Zürich 2000, S. 293-353; siehe auch Robert Levine: Exploiting Ovid. Medieval allegorizations of the Metamorphoses. In: Medioevo Romanzo 14 (1989), S. 197-213.

39 Epistolae obscurorum virorum. Hg. von Aloys Bömer. Bd. 2: Text. Heidelberg 1924, Reprint Aalen 1978, S. 49-51.

40 Ich benutzte die folgende, von Jakob Micyllus ergänzte Ausgabe: P. Ovidii Nasonis Metamorphose $\omega$ s libri quindecim, cum commentariis Raphaelis Regii. Adiectis etiam annotationibus Iacobi Micylli nunc primum in lucem editis, cum locupletissimo praeterea in haec omnia 
zichtete gänzlich auf eine geistliche Auslegung. Der Schwerpunkt liegt bei ihm, abgesehen von der großen Zahl philologischer Erläuterungen, auf dem Aspekt der moralischen Belehrung, für die die von Ovid erzählten Geschichten nicht als Allegorien, sondern als bloße Exempla herangezogen werden, die ihrerseits, im Sinne des historischen Deutungsaspekts, eine Würdigung als Zeugnisse ihrer eigenen Zeit erfahren. Der naturkundliche Deutungsaspekt spielt bei Regius wie später bei Sabinus nur eine untergeordnete Rolle. Jenseits der Möglichkeiten, die sich durch die Anwendung der verschiedenen Auslegungsaspekte ergeben, sah Regius das Werk Ovids als eine Art Enzyklopädie, aus der eine Fülle von Wissen unterschiedlichster Art über antike Geschichte, Kultur und Philosophie zu gewinnen war. Von großer Bedeutung war für Regius auch die Würdigung der stilistischen und rhetorischen Leistungen seines Autors.

Es liegt auf der Hand, daß sich Sabinus, läßt man den von ihm ignorierten Sektor der philologischen Erläuterungen beiseite, insoweit innerhalb der von Regius vorgezeichneten Bahnen bewegt. Als eine bemerkenswerte Besonderheit des Interpretationswerkes von Sabinus ist allerdings seine als Programm formulierte und faktisch weithin auch vollzogene Wiederbelebung des vom Humanismus eigentlich als mittelalterliche Verirrung abgelehnten Verfahrens der Allegorese unter veränderten Vorzeichen hervorzuheben. Er begründet dessen Anwendung im Widmungsbrief an Herzog Albrecht, wie schon erwähnt, vor allem mit didaktischen Argumenten: mit der dadurch bewirkten Schulung des Urteilsvermögens und dem Nutzwert solcher Schulung bei der Auslegung der Glaubensinhalte der Kirche, d.h. vor allem der Heiligen Schrift. Voraussetzung ist für Sabinus stets die Wahrung eines strengen Textbezugs, die Respektierung der Aussageabsichten des Autors und die strikte Trennung weltlicher und geistlicher Aspekte. ${ }^{41}$ Sabinus spricht hier als Schüler Melanchthons, indem er dessen Ausführungen über die Allegorie in dem der Kritik des vierfachen Schriftsinns gewidmeten Abschnitt der ,Elementa rhetorices“42 von der Heiligen Schrift sinngemäß auf weltliche Texte überträgt. Melanchthon beharrt bekanntlich darauf, daß der grammatische Sinn bzw. der Literalsinn des Textes der Heiligen Schrift stets als Grundlage jeder Interpretation festgehalten werden müsse und Allegorien nur insoweit zulässig seien, als sie auf den durch den Literalsinn vorgegebenen Strukturen aufbau-

indice. Basel: per Ioan. Hervagium 1543. - Zu dem Kommentar von Regius siehe Guthmüller: Lateinische und volkssprachliche Kommentare (Anm. 36), S. 125-133; Moss: Ovid in Renaissance France (Anm. 9), S. 28-31; dies. (Hg.): Latin commentaries on Ovid from the Renaissance (Anm. 9), S. 29-60.

41 D 64-74.

42 Philipp Melanchthon: Elementa rhetorices. Grundbegriffe der Rhetorik. [...]. Hg., übers.u. komment. von Volkhard Wels. Berlin 2001, S. 192-211. 
ten und nicht als Beweismittel, sondern nur als verdeutlichende Bilder ohnehin zweifelsfrei feststehender Interpretationen verstanden würden. Mit seiner Ablehnung einer geistlich-allegorischen Auslegung Ovids unterscheidet sich Sabinus klar von dem Dominikaner-Humanisten Petrus Lavinius, der mit seinen seit 1510 als Beigabe zu dem Werk von Raphael Regius erscheinenden Auslegungen zum 1. Buch der Metamorphosen die Tradition auch der geistlichen Ovid-Interpretation auf der Basis der Theorie des vierfachen Schriftsinns fortsetzte. ${ }^{43}$ Das Interpretationskonzept des Sabinus scheint die 1563 in Frankfurt am Main erschienenen lateinisch-deutschen ,Tetrasticha in Ovidii Metamorphoseon libros XV' des Arztes und neulateinischen Dichters Johannes Posthius (1537-1597) ${ }^{44}$ beeinflußt zu haben..$^{45}$ Den alten Spuren von Berchorius und Lavinius folgte hingegen der Meistersinger Johannes Spreng (1524-1601) mit seinen im selben Verlag und im selben Jahr wie des Posthius Werk (in lateinischer Sprache, ein Jahr später, 1564, in deutscher Ausgabe ${ }^{46}$ erschienenen Metamorphosen-Auslegungen. ${ }^{47} \mathrm{Ob}$ die Erläuterungen des Theologen Gerhard Lorichius (1485-1549[?]) zu der 1545 in 1. Auflage erschienenen Metamorphosen-Verdeutschung Georg Wickrams ${ }^{48}$

$43 \mathrm{Zu}$ Lavinius siehe Moss: Ovid in Renaissance France (Anm. 9), S. 31-36; dies. (Hg.): Latin commentaries on Ovid from the Renaissance (Anm. 9), S. 103-123.

44 Johannes Posthius: Tetrasticha in Ovidii Metamor. lib. XV., quibus accesserunt Vergilii Solis figurae elegantiss. et iam primum in lucem editae. [...]. Frankfurt a. M.: Georgius Corvinus, Sigismundus Feyerabent et haeredes Wygandi Galli 1563.

45 Zu Posthius' Werk siehe Guthmüller: Picta poesis Ovidiana (Anm. 36), S. 176-181; Hans-Jürgen Horn: Die Tetrasticha des Johannes Posthius zu Ovids Metamorphosen und ihre Stellung in der Überlieferungsgeschichte. In: Die Rezeption der Metamorphosen des Ovid in der Neuzeit (Anm. 36), S. 214-224; Regina Toepfer: Veranschaulichungspoetik in der frühneuhochdeutschen Ovid-Rezeption. Philomelas Metamorphosen bei Wickram, Spreng und Posthius. In: dies. u.a. (Hgg.): Humanistische Antikenübersetzung und frühneuzeitliche Poetik in Deutschland (14501620). Berlin, Boston 2017 (Frühe Neuzeit 211), S. 383-407.

46 Ich benutzte die deutsche Ausgabe: Johannes Spreng: P. Ovidii Nasonis [...] Metamorphoses oder Verwandlung, mit schönen Figuren gezieret, auch kurtzen Argumenten und Auslegungen erkläret und in Teutsche Reymen gebracht [...]. Frankfurt a. M.: Georg Rabe, Sigmund Feyrabend u. Erben des Weigand Han. 1564.

47 Hierzu siehe Moss: Ovid in Renaissance France (Anm. 9), S. 44-48; Guthmüller: Picta poesis Ovidiana (Anm. 36), S. 181-185; Toepfer: Veranschaulichungspoetik in der frühneuhochdeutschen Ovid-Rezeption (Anm. 45).

48 Erstmals zusammen mit Wickrams Text wissenschaftlich herausgegeben in: Georg Wickram: Sämtliche Werke. Hg. von Hans-Gert Roloff. Bd. 13, 1. u. 2. Tl.: Ovids Metamorphosen. Textredaktion: Lothar Mundt. Berlin, New York 1990. - Wichtige Hinweise zu Lorichius und seinen Auslegungen in der älteren Ausgabe von Johannes Bolte: Georg Wickram: Werke. Bd. 8 (Ovids Metamorphosen, Buch 9-15). Tübingen 1906, Reprint Hildesheim, New York 1974, S. XXXVIII-XLV. - Untersuchungen: Karl Stackmann: Die Auslegung des Gerhard Lorichius zur „Metamorphosen“-Nachdichtung Jörg Wickrams. Beschreibung eines deutschen Ovid-Kommen- 
Sabinus bekannt waren und von ihm vielleicht sogar benutzt worden sind, steht dahin. Man mag zwischen beiden Interpretationen mancherlei Parallelen finden, z. B. die Auffassung, daß Ovids Werk ebenso als ein historisches und kosmographisches Lehrbuch wie als Unterweisung in der „Philosophie und Edele $<$ n $>$ Künst“49 gelesen werden könne, wie vor allem anderen das Interesse an einer moralischen Auslegung der einzelnen Episoden. Die Perspektive des Lorichius ist jedoch weniger auf das Werk selbst gerichtet als vielmehr auf die Nutzanwendung für den gemeinen Mann, für den die Bearbeitung Wickrams gedacht war und der durch die beigegebenen Auslegungen davor bewahrt werden sollte, bestimmte Inhalte des Ovidschen Werkes als Anreiz zu unmoralischem Verhalten mißzuverstehen. Die persönlich engagierte, oft eifernde Tonlage in den Auslegungen des Lorichius ist eher die eines Seelsorgers und Kanzelredners als die eines humanistischen Literaten wie Sabinus.

\section{Nachleben}

Den Metamorphosen-Interpretationen von Sabinus war ein nicht unbeachtliches publizistisches Nachleben beschieden. Bis zum Jahr 1718 wurden sie als Standardwerk zum Thema, setzt man das Erscheinungsjahr der Editio princeps mit 1555 an, ${ }^{50}$ mindestens einundzwanzigmal nachgedruckt, ${ }^{51}$ und zwar nicht nur in Deutschland, ${ }^{52}$ sondern auch in Frankreich ${ }^{53}$ und England, ${ }^{54}$ meist als in sich geschlossener Text wie in der Erstausgabe (teils für sich allein, teils als Beigabe zu einer Ovid-Ausgabe), zuweilen aber auch, in Einzelannotationen zerlegt, als fortlaufender Kommentar zu Editionen des Ovid-Textes. ${ }^{55}$

tars aus der Reformationszeit. In: Zeitschrift für deutsche Philologie 86 (1967), Sonderheft ,Spätes Mittelalter', S. 120-160; Brigitte Rücker: Die Bearbeitung von Ovids Metamorphosen durch Albrecht von Halberstadt und Jörg Wickram und ihre Kommentierung durch Gerhard Lorichius. Göppingen 1997 (Göppinger Arbeiten zur Germanistik 641); Toepfer: Veranschaulichungspoetik in der frühneuhochdeutschen Ovid-Rezeption (Anm. 45).

49 Zitiert aus Lorichs Dedikation für Eberhard Rüde von Collenbergk: Wickram: Sämtliche Werke, Bd. 13, 1. Tl. (Anm. 48), S. 23.

50 S. o., Anm. 19.

51 S. u. die Liste im Editionsbericht, S. 359 f.

52 Druckorte waren neben Wittenberg, wo die ersten fünf Ausgaben erschienen sind: Frankfurt a. M., Leipzig und Heidelberg.

53 Drei Ausgaben: Paris 1575, 1579 und 1580.

54 Eine Ausgabe: Cambridge 1584.

55 So z. B. in der folgenden Ausgabe: P. Ovidius: Metamorphosis, seu fabulae poeticae earumque interpretatio ethica, physica et historica Georgii Sabini, poetae nostri seculi fere principis. 


\section{De carminibus ad veterum imitationem artificiose componendis praecepta}

Wie schon erwähnt, teilt Sabinus im Widmungsbrief zu seiner Interpretation von Ovids Metamorphosen mit, daß er seinen Studenten dieses Werk eigentlich nur „wegen der lateinischen Sprache und der Art der Verse“ („propter linguam Latinam et genus versuum“56) vorlege, und begründet die Beschäftigung mit den Dingen, die den eigentlichen Inhalt seines Ovid-Buches bilden, nämlich die historischen und moralischen Auslegungen der einzelnen Sagenstoffe, damit, daß sie die Lektüre angenehmer und interessanter machten - womit sie genau genommen wenigstens teilweise auf den Wert einer nur unterrichtsmethodisch motivierten Zugabe herabgestuft werden. Im Hinblick auf diese Ausführungen scheint das kleine Werk ,De carminibus ad veterum imitationem artificiose componendis praecepta bona et utilia ${ }^{67}$ das ebenfalls auf eine Königsberger Vorlesung zurückgeht, viel eher in den Kernbereich dessen zu gehören, was Sabinus als Aufgabe des universitären Literaturunterrichts ansah.

Die näheren Umstände der Entstehung und Publikation dieser Schrift sind einem kurzen Brief des Sabinus an seinen Förderer Joachim Camerarius zu entnehmen, der dem Text der Druckausgabe in der Art eines Widmungsbriefes vorangeht. Dieser aus Königsberg auf den 14. März, ohne Jahresangabe, datierte Brief hat folgenden Wortlaut:

Obsignatis literis, quas ad te daturus eram, forte libellum, quem his adiunxi, reperi inter meas chartas, in quo perscripta vel designata potius essent quaedam, quae ante biennium hîc dictavi auditoribus meis, rudia quidem illa et minuta, sed neutiquam tamen, ut opinor, inutilia et contemnenda. Nam de quibus olim me admonuerunt praeceptores mei inter emendandum, ea complexus sum libello isto. Hic si videbitur, curabis, ut edatur istic apud vos. Titulum facies quem volueris: tuo enim hoc arbitrio permitto. Si non probabitur, ne edas velim, sed remittas mihi. Vale, ex monte Regio Prussiae. Pridie Idus Martii. ${ }^{58}$

[Nachdem ich einen Brief versiegelt hatte, den ich gerade an dich senden wollte, fand ich zufällig unter meinen Papieren ein kleines Schriftstück, das ich vorliegendem Brief beige-

Opus omnibus poetices studiosis necessarium. Accessit etiam ex Natalis Comitis mythologiis de fabularum utilitate, varietate, partibus et scriptoribus deque apologorum, fabularum aenorumque differentia tractatio. Cum indice verborum et rerum praecipuarum in Ovidio et Sabino comprehensarum. Frankfurt a. M.: ex officina typographica Ioannis Wecheli 1589. - Ein Reprint dieser Ausgabe erschien unter dem Namen des Sabinus: Georgius Sabinus: Metamorphosis seu Fabulae poeticae (Frankfurt 1589). New York, London 1976 (The Renaissance and the Gods).

56 D 20.

57 Ich benutzte den Nachdruck in des Sabinus ,Poëmata‘ (Anm. 13), S. 489-517.

58 Ebd., S. 489. 


\begin{abstract}
fügt habe. Darin ist einiges schriftlich niedergelegt oder vielmehr skizziert, was ich hier vor zwei Jahren meinen Schülern diktiert habe, unausgearbeitet zwar und von geringem Umfang, aber doch, wie ich meine, keineswegs unnütz und unbeachtlich. Ich habe nämlich in dieser kleinen Schrift alles das zusammenfassend dargestellt, worauf mich dereinst meine Lehrer bei ihren Korrekturen hingewiesen haben. Wenn es dir gut scheint, sorge bitte dafür, daß sie bei euch publiziert wird. Den Titel magst du so formulieren, wie du willst; dies überlasse ich nämlich deinem Gutdünken. Wenn sie nicht deinen Beifall finden wird, möchte ich, daß du sie nicht publizierst, sondern mir zurückschickst. Lebe wohl! Aus Königsberg in Preußen, am 14. März.]
\end{abstract}

Überbringer dieses Schreibens nebst beigefügtem Manuskript war des Camerarius Sohn Johannes, der in Königsberg studierte. Dies geht aus einem Brief vom 22. Juli $1551^{59}$ hervor, in dem Sabinus Camerarius an die noch ausstehende Stellungnahme zu dem übersandten Manuskript erinnerte: „Misi tibi libellum per filium tuum Iohannem de componendis versibus, de quo iudicium tuum expecto.“60 [„„Ich habe dir durch deinen Sohn Johannes eine kleine Schrift über das Abfassen von Versen geschickt, zu der ich dein Urteil erwarte."] Das Werklein erschien dann noch im selben Jahr zusammen mit einer Schrift von Camerarius selbst bei dem Leipziger Drucker Pabst. ${ }^{61}$

Der von Camerarius gewählte Titel gibt seinen Inhalt sehr genau wieder: Es geht um die sprachlich-stilistische Ausgestaltung von Versen, nicht etwa um Verslehre im Sinne der Metrik. Dieses Thema wird nur im letzten der sieben kurzen Kapitel berührt, in dem es um die Vermeidung von Fehlern beim Schreiben von Pentametern geht, hier aber auch nur insoweit, als darauf aufmerksam gemacht wird, daß die beim Pentameter vorgeschriebene Zäsur einzuhalten sei und nicht überspielt werden dürfe, wie es bei dem auch sonst nicht immer zur Nachahmung zu empfehlenden Catull manchmal vorkomme. Sonst werden in diesem Kapitel nur negative Anweisungen zur Wortwahl am Pentameter-Ende gegeben: Die Wörter, mit denen er schließt, sollen keine Participia praesentis sein, nicht mehr als zwei Silben haben, aber auch nicht einsilbig sein.

Sabinus beginnt seine Anweisungen mit einem „De versibus non fundendis ex tempore“ überschriebenen Kapitel, einer Warnung vor einer zu schnellen, plötzlicher Eingebung folgenden Versproduktion. Der ,poeta' unterscheide sich dadurch vom ,versificator', daß er mit Besonnenheit und Kunstverstand dafür

\footnotetext{
59 Ebd., S. 525 f.

60 Ebd., S. 526.

61 Georgius Sabinus: De carminibus ad veterum imitationem artificiose componendis praecepta bona et utilia collecta à Georgio Sabino. Enumeratio eorum, quae in docendo praecipuè sequenda esse videantur. Graecè et Latinè exposita à Ioachimo Camerario Pabebergensi. Leipzig: Valentinus Papa 1551.
} 
sorge, daß alle Elemente eines Verses harmonisch so aufeinander abgestimmt sind, daß sie den Ohren angenehm klingen und die Geister für sich einnehmen. Zwar dürfe man den Schwung schöpferischer Eingebung nicht durch Sorglichkeit im Hinblick auf Stil und Komposition allzusehr aufhalten, doch sei auf jeden Fall Übereilung zu meiden, da sie nur kraft- und geistlose Verse hervorbringe und nicht die empfehlenswerte ,facilitas ' der Verse bewirke, sondern nur eine in jeder sprachlichen Hervorbringung abstoßende ,futilitas‘.

Das zweite Kapitel ist dem ,delectus verborum', der Wortwahl im Vers zur Erzielung rednerischer Eleganz (,elegantia sermonis'), gewidmet. Man dürfe nur Wörter benutzen, die sich durch ,gratia' und ,venustas', also Gefälligkeit und Anmut, für den Gebrauch innerhalb der Poesie auszeichneten, müsse folglich auch innerhalb der besten Autoren eine Auswahl treffen, denn z. B. seien nicht alle Wörter und Wendungen, die sich innerhalb der Redekunst eingebürgert hätten, auch für den Dichter geeignet. Für die Aufnahme eines Wortes in einen Vers sei vor allem der Wohlklang entscheidend. Abzulehnen sei die von Vives vertretene Ansicht, daß in der Poesie im Unterschied zur ungebundenen Rede alle Wort- und Ausdrucksarten erlaubt seien, da das Metrum alle Unebenheiten zudecke. Unbedingt zu meiden seien alle schmutzigen und einer niederen Sphäre angehörenden Wörter, soweit die Thematik ihren Gebrauch nicht geradezu erzwinge, denn sie verunstalteten den Vers so wie Flecken ein kostbares Gewand. Mißgriffe auf diesem Gebiet seien auch bei anerkannten Autoren zu finden, so z. B. bei Martial oder Baptista Mantuanus. Zu warnen sei vor einer übertriebenen Einmengung latinisierter griechischer Wörter, wodurch ein lächerlicher Sprachmischmasch entstehe, wie er in der makkaronischen Poesie üblich sei. Zu meiden seien auch obszöne Wörter. Sollte es aber einmal unvermeidlich sein, anstößige Sachverhalte oder Gegenstände zu benennen, so müsse man sich gewisser Umschreibungen bedienen, wie man sie z. B. bei Pietro Bembo oder Jacopo Sannazaro finden könne. Die auserlesensten Ausdrücke, die dem Dichter zu Gebote stünden, seien metaphorische. Diese dürften aber auch nicht im Übermaß verwendet werden. Wie der Maler Plastizität der dargestellten Gegenstände erzeuge, indem er dem Licht an der rechten Stelle Schatten beigebe, so müsse der Dichter auch da, wo es geboten sei, dem übertragenen Ausdruck den eigentlichen beimischen und dürfe nicht immer denselben rednerischen Zierat verwenden.

Nachdem hiermit der Aspekt der ,elegantia sermonis‘ abgehandelt ist, sind die folgenden drei Kapitel drei Voraussetzungen für die Erzielung der ,suavitas compositionis' gewidmet. Es sind dies: (1) die gefällige Anordnung der Wörter (structura verborum), (2) die Beigabe von Epitheta, (3) das harmonische Zusammenspiel (concinnitas) von Versfüßen, Versformen, Satzgliedern und Figuren.

Hinsichtlich der ,structura verborum' müsse man auf möglichst weiche und fließende Übergänge, ohne Hiatus und klangliche Härte, achten, wenn auch 
zuweilen (wie ein Beispiel bei Vergil zeige) ein Hiatus zweckmäßig sein könne zur Erzeugung größerer Klangfülle und die Häufung rauher Konsonanten ihren guten Sinn habe, wenn sie zur Wiedergabe entsprechender Sachverhalte eingesetzt werde. Die Wiederholung ähnlich klingender Buchstaben und Silben müsse auch nicht immer gemieden werden. Es könnten sich daraus durchaus Verse ergeben, die den Ohren angenehm klingen, wie Sabinus an einem von ihm selbst in Anlehnung an einen Dialog des Erasmus von Rotterdam verfaßten EchoGedicht demonstriert.

Die Beigabe von Epitheta zu Substantiven sei nötig, damit die Rede im Vers nicht nackt und schmucklos daherkomme. Das Epitheton stehe am besten vor dem Substantiv, könne aber von diesem durch dazwischengeschaltete Redeteile auf eine sehr gefällige Weise getrennt werden.

Die zahlreichen Ratschläge zur Erzielung einer ,concinnitas pedum, membrorum et numerorum', die Sabinus nun folgen läßt, können hier nicht im einzelnen referiert werden. Ihr Grundprinzip wird am Schluß des diesem Thema gewidmeten Kapitels wie folgt angegeben:

His itaque et similibus vocum, pedum, circuitionum membrorumque commutationibus facile effici potest, ne versus sint uniformes, sed ut induant diversum quasi habitum, rebus accommodatum, utque affectibus exprimendis satisfaciant. ${ }^{62}$

[Durch diese und ähnliche Variationen bei Wörtern, Versfüßen, in der Umschreibung und bei den Satzgliedern kann daher leicht bewirkt werden, daß die Verse nicht einförmig sind, sondern gleichsam eine unterschiedliche, den Gegenständen angemessene Kleidung anlegen und daß sie den Affekten, die zum Ausdruck gebracht werden sollen, Genüge tun.]

Thema des folgenden, vorletzten Kapitels ist die Erzeugung einer gefälligen ,variatio‘ durch Anwendung von Figuren. Die Figur, mit der dieses Ziel vornehmlich erreicht werden könne, sei die Iteratio, die nun nebst den ihr verwandten Figuren Epanalepsis, Complexio, Epanodos bzw. Recessio, Traductio, Articulus und Polysyndeton anhand vieler Beispiele aus antiken lateinischen Dichtern und aus zwei berühmten modernen Autoren, Baptista Mantuanus und Janus Pannonius, vorgeführt wird.

Den Schluß von Sabinus' Anleitungen zum Versemachen bildet, wie schon gesagt, ein Kapitel mit einer sehr speziellen Thematik: der Vermeidung bestimmter Fehler beim Bau des Pentameters. Dieses klingt aus mit einem kurzen Abschnitt, in dem der Autor die Unvollständigkeit seiner Darstellung rechtfertigt bzw. sich für sie entschuldigt. Unter anderem hätte man nämlich noch eingehen

62 Sabinus: Poëmata (Anm. 13), S. 506. 
müssen auf das Verfahren der Ausschmückung von Versdichtungen durch auserlesene Sentenzen. Doch nicht alles könne durch Regeln gelehrt werden. Was hier noch fehle an dichterischer Kunstlehre, müsse durch Lektüre, Anwendung und Übung gelernt werden.

Des Sabinus kleines poetisches Lehrbuch hatte kein geringeres publizistisches Nachleben als seine Ovid-Interpretation. Seit dem ersten Erscheinen der erweiterten Ausgabe seiner ,Poemata (Leipzig 1563) ${ }^{63}$ ist es in allen Drucken dieser Sammlung (nach der Sabinus-Bibliographie von Marga Heyne ${ }^{64}$ insgesamt sieben bis 1612) enthalten. Parallel dazu wurde es seit dem letzten Viertel des 16. Jahrhunderts als Beigabe zu dem bis weit ins 17. Jahrhundert hinein in zahlreichen Ausgaben erschienenen Epitheta-Lexikon des französischen Philologen Joannes Ravisius Textor (ca. 1480-1522/24) immer wieder nachgedruckt. ${ }^{65}$

1569 erschien es als Beigabe zu der ,Ratio examinandorum componendorumque versuum methodica' von Jakob Micyllus (1503-1558). ${ }^{66} 1577$ ließ des Sabinus Schüler und Nachfolger auf dem Poetik-Lehrstuhl in Frankfurt a. O., Johannes Schosser (1530-1585), ${ }^{67}$ eine mit Scholien versehene Ausgabe der ,Praecepta6 erscheinen, der noch zwei Zugaben angehängt waren: ,Prolegomena in interpretationem Aeneidos Virgilianae', 1568 vorgetragen an der Universität Frankfurt a. O. (eingeleitet mit einer Rede an die Studenten), und Thesen zu einer im folgenden Jahr, 1569, ebendort abgehaltenen Disputation über die Tragödientheorie des Aristoteles. ${ }^{6}{ }^{8}$ Der Kontext dieser zwei Academica legt die Vermutung nahe, daß

63 S. o., Anm. 13.

64 Marga Heyne: Das dichterische Schrifttum der Mark Brandenburg bis 1700. Eine Bücherkunde. Potsdam, Berlin 1939 (Brandenburgische Jahrbücher 13), S. 23-29, hier S. 26, Nr. 176-182. 65 Das ziemlich umfangreiche Lexikon von Ravisius Textor, offenbar gedacht als Hilfsmittel für neulateinische Dichter, verzeichnet lateinische Substantive und Eigennamen in alphabetischer Folge, denen jeweils eine Liste mit Epitheta zugeordnet ist: jedes Epitheton auf einer eigenen Zeile stehend, gefolgt von einem Beleg aus der lateinischen (antiken und neuzeitlich-humanistischen) Poesie. Ich habe die folgende Ausgabe eingesehen: Ioannes Ravisius Textor: Epithetorum opus absolutissimum. Post varias editiones ipsiusque auctoris recognitionem et doctissimorum virorum emendationes locupletatum et innumeris mendis repurgatum. Accesserunt de prosodia lib. IIII. Quos Epithetorum praeposuimus operi. Item, de carminibus ad veterum imitationem artificiosè componendis praecepta, collecta à Georgio Sabino. Venedig: apud Petrum Ricciardum 1605, Bl. $37^{\mathrm{v}}-42^{\mathrm{r}}$ (der Text von Sabinus, hier, mit Marginalien versehen, als Abschluß von Buch III der den ,Epitheta' vorgeschalteten ,Prosodia').

66 Iacobus Micyllus: Ratio examinandorum componendorumque versuum methodica [...]. [Frankfurt a. M.: Christian Egenolff d. Ä. Erben] 1569.

67 S. o., Anm. 7.

68 Iohannes Schosserus: Libellus Cl. V. Georgii Sabini Brandeburgensis De carminibus ad veterum imitationem artificiosè componendis. Et in eum Scholia Iohannis Schosseri Aemiliani. Ac- 
Schosser die ,Praecepta، des Sabinus als Grundlage einer Vorlesung verwendet hat und die in der Ausgabe abgedruckten Scholien aus einer solchen Lehrveranstaltung hervorgegangen sind.

Letztmalig wurden die ,Praecepta‘ gedruckt innerhalb einer von dem Rudolstädter Gymnasialrektor Johann Heinrich Acker d.J. (1680-1756) 1711 herausgegebenen kleinen Sammlung ,Selecta poetica', ${ }^{69}$ die u. a. auch die ,Ars versificatoria“ von Ulrich von Hutten enthält. Des Sabinus Text ist hier erweitert um ,Observationes` des Herausgebers.

Der Frage, inwieweit das rege publizistische Interesse an den beiden Königsberger Lehrschriften des Sabinus mit einer Rezeption seiner Gedanken innerhalb der Geschichte der Ovid-Kommentierung bzw. -Auslegung und der Geschichte der Poetik verknüpft war, müßte in anderem Zusammenhang weiter nachgegangen werden. Kein Zweifel scheint mir aber daran zu bestehen, daß zentrale Auffassungen des Sabinus über das Wesen der Poesie noch um die Mitte des 17. Jahrhunderts an der Universität Königsberg als weiterhin gültige Lehrinhalte vermittelt wurden. Einen Beleg dafür liefert der folgende Satz aus Simon Dachs Einladung zu seiner Königsberger Antrittsvorlesung im Jahre 1639: ${ }^{70}$

Poesis est Philosophia [...], tempore quidem vetusta, compositio autem numeris concinna, atque sententia fabularum involucris tecta. ${ }^{71}$

[Die Poesie ist Philosophie, und zwar die in früher Zeit; ihre Darstellung aber ist dank der Versmaße von gefälliger Form, und ihr Sinn ist unter der Umhüllung von Erdichtungen verborgen.]

cesserunt eiusdem Schosseri in Aeneidos Virgilianae interpretationem $\pi \rho \circ \lambda \varepsilon y o ́ \mu \varepsilon v \alpha$. Disputatio

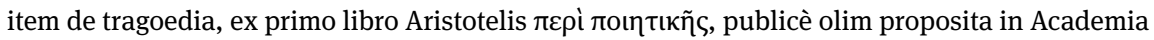
Francofordiana. Frankfurt a.O.: excudebat Iohannes Eichorn 1577. - Der Text von Sabinus mit den Scholien Schossers hier Bl. A6 ${ }^{\mathrm{v}}-\mathrm{E} 5^{\mathrm{r}}$.

69 Selecta poetica. Quibus continentur Ge. Sabini Praecepta observationibus aucta, Ulrici de Hutten Equitis Franci Ars versificatoria eiusque Nemo; Claudii Espencaei Elegiae selectiores. Samuelis Rachelii Classes Imperatorum metricae. Collegit suaque adiecit carmina Jo. Henr. Acker. Rudolstadt 1711.

70 Siehe hierzu Hanspeter Marti u. Lothar Mundt: Zwei akademische Schriften von Simon Dach aus den Jahren 1639 und 1640. Analyse und Dokumentation. In: Simon Dach (1605-1659). Werk und Nachwirken. Hg. von Axel E. Walter. Tübingen 2008 (Frühe Neuzeit 126), S. 67-114.

71 Simon Dachius: Ad inauguralem orationem lectionibus publicis in professione poëtica praemittendam Moecenates, patres ac cives academicos officiosissimè invitat. Königsberg: typis haeredum Segebadii 1639 (Warschau, Bibl. Narodowa), Bl. $2^{\mathrm{r}}$. 
Als Quelle für diesen Satz, den er sich gänzlich zu eigen macht, nennt Dach einen „Platonicus“. ${ }^{72}$ Welcher Gewährsmann damit gemeint ist (ein antiker Autor ist auszuschließen), konnte bislang nicht ermittelt werden. Statt auf diesen ominösen Platoniker hätte Dach sich aber auch auf Georg Sabinus, den ersten Inhaber des Lehrstuhls, den er nun selbst innehatte, berufen können, denn der von mir schon zitierte erste Satz von dessen Metamorphosen-Interpretation lautet sehr ähnlich:

Poetica nihil aliud est nisi Philosophia numeris et fabulis concinna, qua honestarum artium doctrina et praecepta de moribus illustrata regnorum exemplis continentur. ${ }^{73}$

[Die Poesie ist nichts anderes als eine durch Versmaße und dichterische Erfindungen gefällig gestaltete Philosophie, in der die Lehre ehrbarer Künste und Moralvorschriften, erhellt durch Beispiele von Königreichen, enthalten sind.]

Auch der Gedanke, daß die Poesie, abgesehen von ihren moralphilosophischen Inhalten und Funktionen, eine geradezu universale Schatzkammer menschlichen Wissens sei, den Sabinus in aller Breite an Ovids Metamorphosen demonstriert, für den aber ebensogut auch Vergil oder andere Epiker hätten angeführt werden können, ist zur Zeit Dachs noch ungebrochen. Auch hierfür mag ein Zitat aus Dachs Einladungsschrift als Zeugnis dienen:

Deum rerum omnium conditorem credit pietas. Poetam conditarum imitatorem dicit sapientum consensus. Quacunque vult liberrimè vagatur poesis, suaeque sedem divinitatis constituit. In coelo cum aeternis mentibus moratur, et admirandae corporum coelestium consensionis speciem sibi imprimit. Maris et tempestatum violentiam inconcussa sustinet, ventorumque fremitus suum putat concentum. Inferorum loca aequè liberè ac Maiae filius accedit, Elisiorum felices campos lustrat, exilia sontum imperterrita spectat, et à Tantalo Sisyphoque quàm diu vult iudice Aeaco aut Rhadamanto poenas exigit. Cum Euclide terrarum spatia metitur, cum Tityro pastorem agit, cum Varrone rusticatur, cum Solone aut Lycurgo leges sancit, cum Aesculapio morbis medetur, cum Scipione aciem instruit, cum Tiphy aut Palinuro navem gubernat, cum Platone Rempublicam format, cum Demiphone indignatur, cum Romulo urbem dominam condit, ut difficile sit, quicquam moliri, cuius illa partem sibi non vindicet. Omnia penetrat, notat, digerit [...]. ${ }^{74}$

[Die Frömmigkeit glaubt, daß Gott der Schöpfer aller Dinge sei. Die übereinstimmende Meinung der Weisen sagt, daß der Dichter der Nachahmer der geschaffenen Dinge sei. Wo immer sie will, streift die Poesie umher und errichtet sie den Thron ihrer Göttlichkeit. Im Himmel weilt sie mit den ewigen Geistern und prägt sich den Glanz bewundernswerter

72 Ebd.

$73 \mathrm{I}, 1,3-5$.

74 Dachius: Ad inauguralem orationem (Anm. 71), Bl. $3^{\mathrm{r}}$. 
Übereinstimmung mit himmlischen Leibern auf. Dem Ungestüm des Meeres und der Stürme hält sie unerschütterlich stand, und in dem Brausen der Winde sieht sie ihren eigenen harmonischen Gesang. Die Orte der Unterwelt betritt sie ebenso furchtlos wie der Sohn der Maja ${ }^{75}$ die seligen Gefilde der Elysier durchwandert sie, unerschrocken beschaut sie die Verbannungsorte der Missetäter, und unter dem Richter Aeacus oder Rhadamanthus ${ }^{76}$ bestraft sie Tantalus und Sisyphus, solange sie will. Mit Euklid mißt sie die Ausdehnungen der Länder, mit Tityrus ${ }^{77}$ spielt sie die Rolle des Hirten, mit Varro ${ }^{78}$ treibt sie Landwirtschaft, mit Solon oder Lykurg gibt sie Gesetze, mit Äskulap heilt sie Krankheiten, mit Scipio ${ }^{79}$ stellt sie eine Schlachtreihe auf, mit Tiphys ${ }^{80}$ oder Palinurus ${ }^{81}$ lenkt sie ein Schiff, mit Plato gestaltet sie den Staat, [...] mit Romulus gründet sie die Herrscherin Rom, so daß es schwierig ist, irgend etwas ins Werk zu setzen, an dem sie nicht Teilhabe für sich beanspruchen kann. Alles durchdringt, kennzeichnet und ordnet sie [...].]

75 Merkur, hier in seiner Funktion als Todesbote, der die Seelen der Verstorbenen in die Unterwelt geleitete.

76 Zwei der drei Richter in der Unterwelt.

77 Hirtenname bei Theokrit und Vergil.

78 Der römische Gelehrte und Dichter M. Terentius Varro (116-27 v. Chr.) schrieb ein Buch über die Landwirtschaft (,De re rustica'); es ist das einzige unter seinen zahlreichen Werken, das sich vollständig erhalten hat.

79 Scipio Africanus d. Ä., der 202 v. Chr. Hannibal in der Schlacht bei Zama besiegte. Ebensogut könnte aber auch dessen Enkel, Scipio Africanus d.J., gemeint sein, der 146 v. Chr. Karthago eroberte und zerstörte.

80 Der Steuermann der Argonauten bei ihrer Fahrt nach Kolchis zur Erlangung des Goldenen Vlieses.

81 Steuermann des Aeneas in Vergils Aeneis. 
